\title{
Coastal upwelling off Peru and Mauritania inferred from helium isotope disequilibrium
}

\author{
R. Steinfeldt ${ }^{1}$, J. Sültenfuß ${ }^{1}$, M. Dengler ${ }^{2}$, T. Fischer ${ }^{2}$, and M. Rhein ${ }^{1}$ \\ ${ }^{1}$ Institute of Environmental Physics, University of Bremen, Bremen, Germany \\ ${ }^{2}$ GEOMAR, Helmholtz Centre for Ocean Research, Kiel, Germany \\ Correspondence to: R. Steinfeldt (rsteinf@physik.uni-bremen.de)
}

Received: 22 May 2015 - Published in Biogeosciences Discuss.: 14 July 2015

Revised: 17 November 2015 - Accepted: 2 December 2015 - Published: 21 December 2015

\begin{abstract}
Upwelling is an important process, bringing gases and nutrients into the ocean mixed layer. The upwelling velocities, however, are too small to be measured directly. Here we use the surface disequilibrium of the ${ }^{3} \mathrm{He} /{ }^{4} \mathrm{He}$ ratio measured in two coastal upwelling regions off Peru in the Pacific ocean and off Mauritania in the Atlantic ocean to calculate the regional distribution of vertical velocities. To also account for the fluxes by diapycnal mixing, microstructurebased observations of the vertical diffusivity have been performed on all four cruises analysed in this study. The upwelling velocities in the coastal regions vary between $1.1 \pm$ $0.3 \times 10^{-5}$ and $2.8 \pm 1.5 \times 10^{-5} \mathrm{~m} \mathrm{~s}^{-1}$ for all cruises. Vertical velocities are also inferred from the divergence of the wind-driven Ekman transport. In the coastal regimes, both methods agree within the error range. Further offshore, the helium-derived vertical velocity still reaches $1 \times 10^{-5} \mathrm{~m} \mathrm{~s}^{-1}$, whereas the wind-driven upwelling from Ekman suction is smaller by up to 1 order of magnitude. One reason for this difference is ascribed to eddy-induced upwelling. Both advective and diffusive nutrient fluxes into the mixed layer are calculated based on the helium-derived vertical velocities and the vertical diffusivities. The advective part of these fluxes makes up at about $50 \%$ of the total. The nutrient flux into the mixed layer in the coastal upwelling regimes is equivalent to a net community production (NCP) of $1.3 \pm 0.3 \mathrm{~g} \mathrm{C} \mathrm{m}^{2} \mathrm{~d}^{-1}$ off Peru and 1.6-2.1 $\pm 0.5 \mathrm{~g} \mathrm{C} \mathrm{m}^{2} \mathrm{~d}^{-1}$ off Mauritania.
\end{abstract}

\section{Introduction}

Eastern boundary upwelling systems (EBUS), such as the Canary, California, Humboldt, and Benguela Currents belong to the most productive marine ecosystems, e.g. Fréon et al. (2009). The upwelling is caused by the wind-driven surface circulation. Alongshore trade winds drive an offshore Ekman flux, which leads to a horizontal flow divergence at the coast and as a consequence upwelling of cold and nutrient-rich subsurface water. They also transport climaterelevant trace gases such as $\mathrm{N}_{2} \mathrm{O}$ from the ocean's interior into the mixed layer and ultimately into the atmosphere (Kock et al., 2012).

Crucial to quantify the role of upwelling for nutrient and tracer budgets is the vertical velocity, by which substances and gases are transferred from the subsurface into the mixed layer. It is, however, much too small to be measured directly. In previous studies upwelling has been derived from the wind field via Ekman theory (McClain, 1993; Hagen, 2001), the divergence of the horizontal velocity fields inferred from current metres, drifters, and shipboard measurements (Weingartner and Weisberg, 1991; Gouriou and Riverdin, 1992) and geochemical tracers such as ${ }^{14} \mathrm{C}$ (Broecker et al., 1978; Quay et al., 1983; Toggweiler et al., 1991), $p \mathrm{CO}_{2}$ and AOU (Wanninkhof et al., 1995), CFC-12 and $\mathrm{SF}_{6}$ (Tanhua and Liu, 2015 ) as well as the isotopes ${ }^{7} \mathrm{Be}$ (Kadko and Johns, 2011; Haskell II et al., 2015) and ${ }^{3} \mathrm{He}$ (Klein and Rhein, 2004; Rhein et al., 2010).

The helium method (Klein and Rhein, 2004; Rhein et al., 2010) exploits the excess of the helium isotope ${ }^{3} \mathrm{He}$ in the upwelled waters to determine the vertical velocity. The oceanic source for ${ }^{3} \mathrm{He}$ is hydrothermal venting, mainly near 
mid-ocean ridges, where primordial ${ }^{3} \mathrm{He}$ is emitted (Lupton, 1983). The ${ }^{3} \mathrm{He}$ enriched waters eventually reach the mixed layer, e.g. by upwelling, where the excess ${ }^{3} \mathrm{He}$ is outgassing from the ocean.

Another process resulting in a net flux of properties from the ocean interior into the mixed layer is diapycnal mixing. Together with the helium measurements microstructure profiling has been performed at a large number of stations, and the diapycnal diffusivity has been inferred from the data off Mauritania (Schafstall et al., 2010). These authors found elevated dissipation rates of turbulent kinetic energy particularly at the continental slope close to the shelf break.

Here we investigate (i) the coastal region off Peru from 5 to $16^{\circ} \mathrm{S}$ that is part of the Humboldt Current upwelling system and (ii) the southern part of the Canary system off Mauritania between 20 and $16^{\circ} \mathrm{N}$. Both the Peruvian and the Mauritanian upwelling regions have in common that they are adjacent to oxygen minimum zones (Karstensen et al., 2008). This oxygen minimum is most pronounced in the Humboldt current south of $10^{\circ} \mathrm{S}$, where denitrification within the upwelling water occurs. By this process also $\mathrm{N}_{2} \mathrm{O}$ is produced, whereas in the Mauritanian upwelling the main production pathway for this substance is nitrification (Kock et al., 2012).

In contrast to the study of Rhein et al. (2010) at the equator, in the upwelling region off Peru and Mauritania the Ekman theory can be applied to infer the vertical velocity. After presenting the data and methods, the Ekman and helium-derived vertical velocities in the upwelling regions are compared. Therefore, the cases for the open ocean (offshore region) and the case of a lateral boundary (for the coastal region) are considered. Also the role of eddies related to vertical velocities (eddy pumping) is investigated (McGillicuddy Jr. et al., 2007). Then the contribution of the upwelling and diapycnal mixing to the nutrient fluxes into the mixed layer are calculated.

\section{Data}

From the Peruvian upwelling area, about 300 helium samples have been taken at 62 stations during the cruise Meteor M91 in December 2012. In this region, upwelling occurs throughout the year, with medium offshore transport in boreal autumn-early winter (Carr and Kearns, 2003). Helium measurements in the upwelling region west of Mauritania have been performed on three cruises (Fig. 1) The first cruise, M68/3 on RV Meteor, was conducted during boreal summer 2006 (July-August), but was mainly located north of $18^{\circ} \mathrm{N}$. During the main upwelling season in boreal winter, two cruises with helium data are available: P347 with the German RV Poseidon took place in January 2007 and was restricted to the near coastal region, whereas on ATA3 (French vessel L'Aatalante, February 2008), a larger area was sampled but with less spatial resolution. Altogether, about 500 helium samples have been taken at 101 stations. All above men- tioned cruises were part of the German research program "Surface Ocean Processes in the Anthropocene (SOPRAN)".

$\mathrm{CTD}-\mathrm{O}_{2}$ profiles were collected using a Seabird SBE 911 system attached to a carousel water sampler with $10 \mathrm{~L}$ Niskin bottles. Water subsamples from the Niskin bottles were used for the analysis of biogeochemical properties (nutrients, helium isotopes). From the biogeochemical parameters only $\mathrm{PO}_{4}$ and helium isotopes are used in this study. The upwelling areas off Peru and off Mauritania are located within oxygen minimum zones (OMZ), and the low oxygen concentration due to the remineralization of organic matter is correlated with high nutrient values. Off Peru, oxygen concentrations in the OMZ are so low that denitrification occurs at some places. Therefore we consider here only phosphate fluxes and not nitrate to avoid having to deal with the influence of the OMZ. On the four cruises, phosphate was measured with different autoanalysers, the precision is about $0.02 \mu \mathrm{mol} \mathrm{kg}{ }^{-1}$.

The isotopes ${ }^{3} \mathrm{He}$ and ${ }^{4} \mathrm{He}$ were analysed with the Bremen high-resolution static mass spectrometer (Sültenfuß et al., 2009). A very high resolution is necessary to distinguish between the mass-3 hydrogen species ${ }^{1} \mathrm{H}^{2} \mathrm{H}(\mathrm{HD})$ and ${ }^{3} \mathrm{He}$. In this study, the isotopic ratio ${ }^{3} \mathrm{He} /{ }^{4} \mathrm{He}$ will be used as a tracer for upwelled waters, which is expressed as $\delta^{3} \mathrm{He}$ [\%], i.e. the relative deviation from the atmospheric ratio:

$\delta^{3} \mathrm{He}[\%]=\frac{\left({ }^{3} \mathrm{He} /{ }^{4} \mathrm{He}\right)_{\text {water }}-\left({ }^{3} \mathrm{He} /{ }^{4} \mathrm{He}\right)_{\text {air }}}{\left({ }^{3} \mathrm{He} /{ }^{4} \mathrm{He}\right)_{\text {air }}} \cdot 100$.

The measurement precision for the ${ }^{3} \mathrm{He} /{ }^{4} \mathrm{He}$ ratio is in general $\pm 0.4 \%$ or better (Sültenfuß et al., 2009). This value is confirmed by the standard deviation of repeat samples taken mainly on cruises M91 and P347.

Figure 1 shows the locations and $\delta^{3} \mathrm{He}$ in the mixed layer for the M91 cruise in the Peruvian upwelling region and the cruises M68/3, P347, and ATA3 off Mauritania. $\delta^{3} \mathrm{He}$ values fall in different ranges for the two oceans. This is the result of the difference of the helium- 3 concentration in the subsurface waters of the two upwelling regions (see Fig. 2). This difference can even be seen in the mixed layer, thus indicating the entrainment of water into the mixed layer from below.

In order to distinguish between advective and diffusive vertical ${ }^{3} \mathrm{He}$ fluxes into the mixed layer, knowledge of the diapycnal diffusivity is an important factor. This quantity is determined from microstructure shear data that were collected on all cruises using different tethered microstructure profilers (MSS90L and MSS90D). Both instrument types are equipped with two airfoil shear sensors, a fast temperature sensor (FP07), an acceleration sensor, tilt sensors, and standard CTD sensors. For a detailed description see Prandke and Stips (1998). From the small-scale velocity fluctuations measured by the MSS instruments, dissipation rates of turbulent kinetic energy $\epsilon$ are derived by integrating shear wavenumber spectra assuming isotropic turbulence. Processing details are 

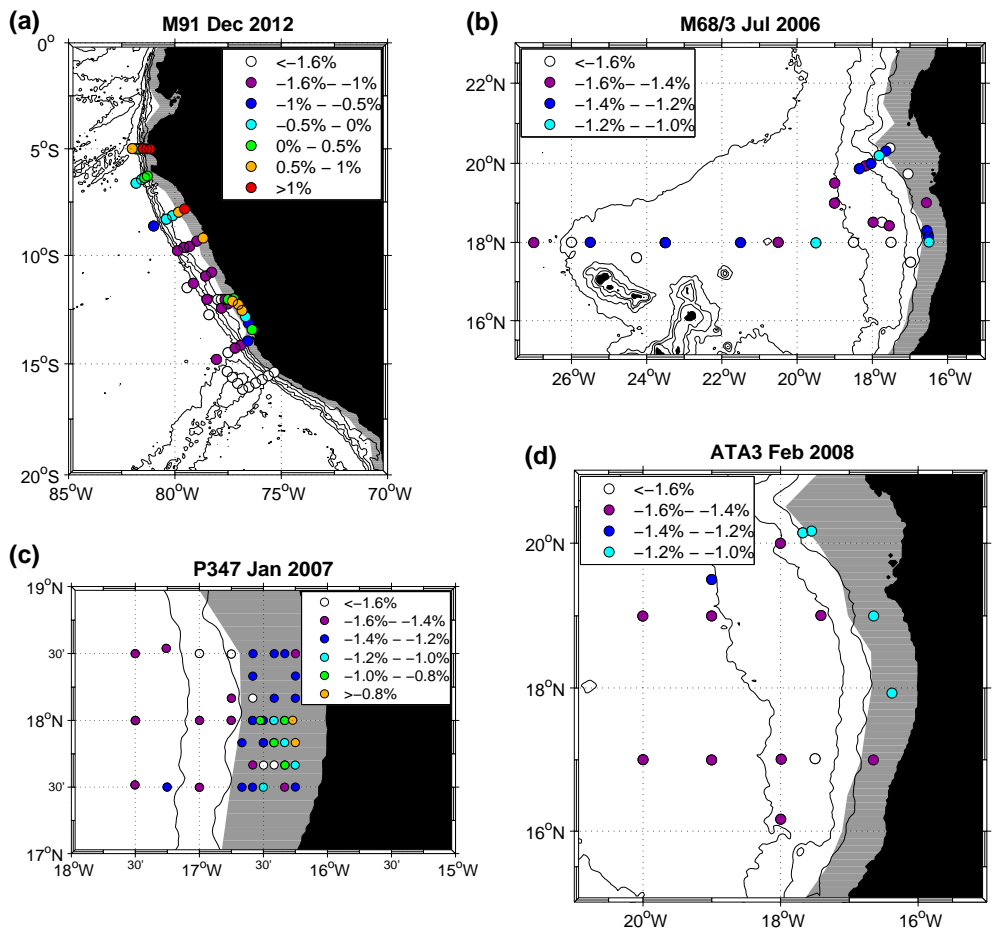

Figure 1. $\delta^{3} \mathrm{He}[\%]$ in the mixed layer for cruise M91 off Peru (a) and for cruises M68/3, P347 and ATA3 off Mauritania (b-d). Isobaths are drawn every $1000 \mathrm{~m}$, and the area of the "coastal region" is shaded grey (for details, see text). Note the different colour scale for the cruises from the Peruvian (a) and Mauritanian (b-d) region. The error of the $\delta^{3} \mathrm{He}$ values in the mixed layer is $0.2 \%$.

described in Schafstall et al. (2010), where the microstructure shear data from the Mauritanian area are presented. After applying corrections for unresolved spectral ranges and loss of variance due to the finite sensor tip finally the diapycnal diffusivity $K_{\rho}$ is inferred via the Osborn (Osborn, 1980) relationship:

$K_{\rho}=\Gamma \frac{\epsilon}{N^{2}}$.

$N$ denotes the local buoyancy frequency, and $\Gamma$ the mixing efficiency, which is set to a constant value of 0.2 (Oakey, 1982).

In addition, remote-sensing data of wind speed, primary production and sea surface height are used in this study. These data are available via the internet. The wind speed $U_{10}$ is taken from the daily gridded ASCAT (ftp://ftp.ifremer.fr/ ifremer/cersat/products/gridded/mwf-ascat/data/daily) wind product (for cruiuse M91 in 2012) and the older QuikSCAT product (ftp://ftp.ifremer.fr/ifremer/cersat/products/gridded/ mwf-quikscat/data/daily, for the Mauritanian cruises in 2006-2008). For primary productivity, the 8 day MODIS based estimates from http://www.science.oregonstate.edu/ ocean.productivity/index.php were used. The algorithm for computing primary production is based on Behrenfeld and Falkoweski (1997). Also used in this study are sea level anomalies from the Aviso product (http://www.aviso. oceanobs.com/duacs/).

\section{Methods}

In order to compute the upwelling velocity from the ${ }^{3} \mathrm{He}$ disequilibrium, the same box model as in Rhein et al. (2010) and Klein and Rhein (2004) is applied. This model only has a vertical dimension with two boxes. The upper box 1 represents the mixed layer, where gas exchange with the atmosphere takes place. The lower box 2 exchanges properties with box 1 by advective and diffusive vertical fluxes. This box thus supplies the upwelling water enriched in ${ }^{3} \mathrm{He}$. In steady state, the upward advective and diffusive fluxes of ${ }^{3} \mathrm{He}$ from box 2 into the mixed layer (box 1) are compensated by outgassing of ${ }^{3} \mathrm{He}$ from box 1 into the atmosphere. This steady-state assumption results in the following equation for inferring the vertical velocity $w$ :

$0=F_{\mathrm{g}}-K_{\mathrm{v}} \frac{\mathrm{d} C}{\mathrm{~d} z}+w\left(C_{2}-C_{1}\right)$.

The same 1-D box model has been used in (Tanhua and Liu, 2015) for CFC-12 and $\mathrm{SF}_{6}$. Kadko and Johns (2011) and Haskell II et al. (2015) use a modified version for the inventory of ${ }^{7} \mathrm{Be}$. All these models neglect horizontal advection, i.e it is assumed that changes of the respective tracer in the mixed layer is dominated by vertical processes. Another interpretation is that Eq. (1) is valid in a Lagrangian coordinate system moving with the surface patch (box 1), as long as 
the lower box 2 moves with a similar velocity and horizontal mixing is small.

Applying the box model, the values of the gas exchange rate $F_{\mathrm{g}}$, the vertical diffusivity $K_{\mathrm{v}}$ (which is assumed to be equal to the diapycnal diffusivity $K_{\rho}$ ) and the vertical $\delta^{3} \mathrm{He}$ gradient below the mixed layer $\mathrm{d} C / \mathrm{d} z$ and the $\delta^{3} \mathrm{He}$ ratio $C_{1}$ and $C_{2}$ in boxes 1 and 2, have to be determined for each profile. We mainly follow the procedure in Rhein et al. (2010), but with some differences in detail.

The gas exchange rate

$F_{\mathrm{g}}=v_{\mathrm{g}} \Delta C$,

is given by the gas transfer velocity $v_{\mathrm{g}}$ and the helium- 3 disequilibrium in the mixed layer $\Delta C=C_{\mathrm{eq}}-C_{1}$. The equilibrium $\delta^{3} \mathrm{He}$ ratio $C_{\mathrm{eq}}$ is $-1.6 \%$. The gas transfer velocity $v_{\mathrm{g}}$ has been calculated using the relationship given by Nightingale et al. (2000):

$$
\begin{aligned}
& v_{\mathrm{g}}= \\
& \quad 0.01 / 3600 \cdot\left(0.222 U_{10}^{2}+0.333 U_{10}^{3}\right) \cdot(S c / 600)^{-0.5}
\end{aligned}
$$

The gridded wind speed $U_{10}$ is interpolated on the locations of the helium measurements, and the daily values are averaged over a time period of $n$ days in advance of the sampling date. $n$ depends on the timescale of the gas exchange, i.e. the mixed-layer depth and the gas transfer velocity itself. $n$ has been calculated as mean value for each cruise and varies between 4 (cruise M68/3) and 8 (cruise P347) days.

The mixed-layer value $C_{1}$ for $\delta^{3} \mathrm{He}$ (also for nutrients) is calculated as the mean of all measurements within the mixed layer at each station. For bottle data as helium and nutrients, these are typically one or two data points per profile. The mixed-layer depth is determined according to Levitus (1982) with a density threshold of $\Delta \sigma \theta=0.125 \mathrm{~kg} \mathrm{~m}^{-3}$. In addition, a visual examination of each profile has been applied to avoid an erroneous allocation of bottle data to the mixed layer. This could be caused by the fact that the mixed-layer depth is determined from CTD data during the downcast, whereas the Niskin bottles are closed during the upcast.

In order to estimate the $\delta^{3} \mathrm{He}$ ratio of box $2 C_{2}$, the vertical mean values of $\delta^{3} \mathrm{He}$ for each profile are computed over an interval of 5 and $25 \mathrm{~m}$ below the mixed layer. The relatively sparse bottle data (helium and nutrients) are vertically interpolated onto $1 \mathrm{~m}$ intervals using a piecewise cubic Hermite polynomial interpolation scheme that preserves the shape of the data as in Tanhua et al. (2010), and then the vertical mean value is calculated. The depth range from 5 to $25 \mathrm{~m}$ below the mixed layer is much smaller than in Rhein et al. (2010), but comparable to those used in Tanhua and Liu (2015) applying the same box model and in Schafstall et al. (2010) and Kock et al. (2012) for calculating diffusive fluxes of nitrate and $\mathrm{N}_{2} \mathrm{O}$ into the mixed layer. Directly at the base of the mixed layer, vertical mixing might dominate (Kadko and Johns, 2011), but the large concentration gradient of ${ }^{3} \mathrm{He}$ (and also nutrients) cannot be resolved by the coarse resolution of the bottle data. We thus determine the diffusive and advective helium- 3 flux from the data in box 2 and assume that these fluxes are continuous into the mixed layer, i.e. no flux divergence or convergence occurs in the "gap" of $5 \mathrm{~m}$ between the boxes 1 and 2 . In Rhein et al. (2010), $C_{2}$ was calculated as regional mean over several profiles. This is not done here, as the regions adjacent to the coast shows a large variability in $C_{2}$ (see Fig. $2 \mathrm{~g}$ and $\mathrm{h}$ ), so the original values for each helium-3 profile are retained.

Turbulent fluxes of ${ }^{3} \mathrm{He}$ into the mixed layer are estimated from the diffusion coefficient based on the microstructure shear data and the vertical $\delta^{3} \mathrm{He}$ gradient. Both $K_{\mathrm{v}}$ and dC/dz in Eq. (1) are averaged over the same range $5-25 \mathrm{~m}$ below the mixed layer as the ${ }^{3} \mathrm{He}$ values for calculating $C_{2}$. At some profiles, only helium, but no microstructure data are available. In these cases, the regional mean value of $K_{\mathrm{V}}$ over coastal and offshore regions respectively has been used.

\section{Property distribution in the coastal upwelling areas}

The distribution of temperature, phosphate and helium- 3 is shown in Fig. 2 for a section along $8^{\circ} \mathrm{S}$ in the Peruvian upwelling, the long $18^{\circ} \mathrm{N}$ section off Mauritania from cruise $\mathrm{M} 68 / 3$ and a short section also along $18^{\circ} \mathrm{N}$ from cruise $\mathrm{P} 347$. The ideal case of coastal upwelling is represented by the section off Peru (Fig. 2, left column): the isolines of all properties and also the isopycnal charecterizing the central water $\left(\sigma_{\theta}=26.0 \mathrm{~kg} \mathrm{~m}^{-3}\right)$ are lifted up towards the coast due to upwelling, and the mixed layer becomes shallower. A similar general feature can be observed along the $18^{\circ} \mathrm{N}$ section for the cruise P347 (Fig. 2, right column), at least for the upper $50 \mathrm{~m}$ of the section and the isopycnal $\sigma_{\theta}=26.0 \mathrm{~kg} \mathrm{~m}^{-3}$. Near the coast below $\approx 50 \mathrm{~m}$ depth, the isolines are declining downward towards the coast for both cruises from the Mauritanian upwelling.

The $18^{\circ} \mathrm{N}$ section of cruise M68/3 (Fig. 2, middle column) has the largest offshore extension of all sections from the two upwelling regions. The isolines and also the bottom of the mixed layer show a conspicuous uplift towards the east between 24 and $20^{\circ} \mathrm{W}$. This is the location of the Canary Current advecting water from the upwelling system further north, which can be seen from the relatively low water temperature in the mixed layer. The water within the coastal upwelling region is fed from the south by South Atlantic Central Water (SACW) (Hagen, 2001) and is more enriched in nutrients and helium-3 and less saline (i.e. colder along isopycnals) than the North Atlantic Central Water, which can be found west of the Canary Current in the interior of the northern subtropical gyre. The Central Water off Peru is clearly more enriched in phosphate and helium-3 than off Mauritania.

In all three sections, $\delta^{3} \mathrm{He}$ values in the mixed layer are in general larger than the equilibrium of $-1.6 \%$. This is especially so in the Pacific due to the high helium-3 content of 

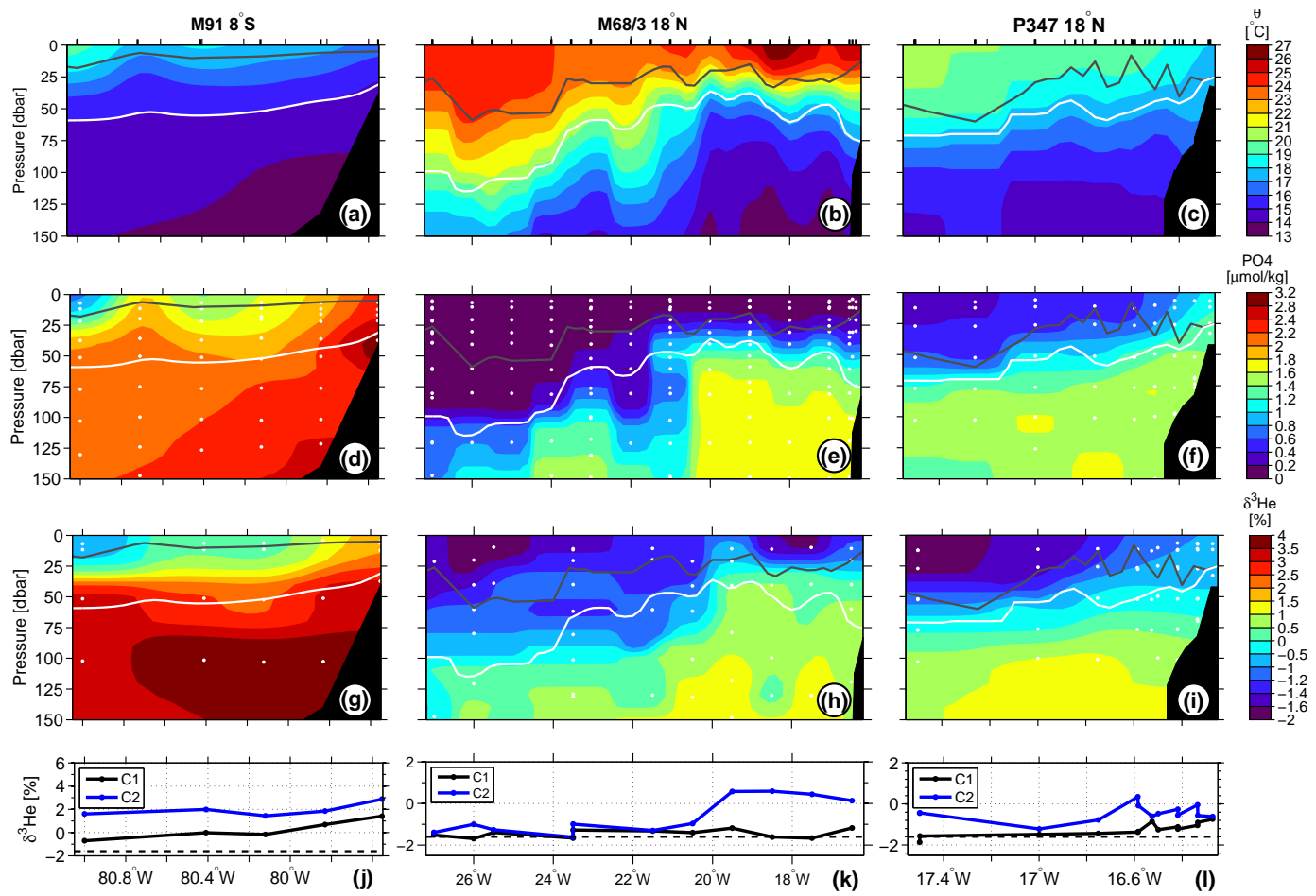

Figure 2. Sections of potential temperature (a-c), phosphate (d-f), helium 3 (g-i) for one section from cruise M91 off Peru (along $\left.8^{\circ} \mathrm{S}\right)$, $\mathrm{M} 68 / 3$ (along $18^{\circ} \mathrm{N}$ ) and P347 (also along $18^{\circ} \mathrm{N}$ ). The grey line denotes the base of the mixed layer and the white line the isopycnal $\sigma_{\theta}=26.0 \mathrm{~kg} \mathrm{~m}^{-3}$. (j-l): mean $\delta^{3} \mathrm{He}$ in box 1 (mixed layer) and box 2 (5-25 m below the mixed layer) along the sections.

the upwelled waters. Offshore in the Atlantic, on some locations, equilibrium values are found, for instance west of $24^{\circ} \mathrm{W}$ during cruise M68/3 (Fig. 2h).

The lowest row in Fig. 2 shows the $\delta^{3} \mathrm{He}$ values of box $1\left(C_{1}\right)$ (the mixed layer) and box $2\left(C_{2}\right)(5-25 \mathrm{~m}$ below the mixed layer), which are used in Eq. (1) to infer the upwelling velocities. For the $8^{\circ} \mathrm{S}$ section of cruise M91 off Peru, both $\left(C_{1}\right)$ and $\left(C_{2}\right)$ are increasing landward, as would be expected for enhanced upwelling at the coast. The difference between $\left(C_{1}\right)$ and $\left(C_{2}\right)$ decreases in onshore direction from about 2 to $1 \%$ in $\delta^{3} \mathrm{He}$, indicating an enhanced exchange between both layers by upwelling and/or diapycnal mixing. In the western subtropical gyre area of the $18^{\circ} \mathrm{N}$ of cruise M68/3, the $\delta^{3} \mathrm{He}$ values in box 1 and 2 are almost identical, as the NACW is depleted in helium-3. Further east, where SACW is dominating below the mixed layer, the difference between $\left(C_{1}\right)$ and $\left(C_{2}\right)$ is larger but decreases towards the coast, as for the section off Peru. Also for the much shorter $18^{\circ} \mathrm{N}$ section of cruise P347 the upwelling and/or mixing near the coast lead to a relatively small difference between the $\delta^{3} \mathrm{He}$ values in box 1 and 2 . The almost identical values of $\left(C_{1}\right)$ and $\left(C_{2}\right)$ at $17^{\circ} \mathrm{W}$ might result from a data gap below the mixed layer (see the location of helium samples in Fig. 2i). Note that some stations along this line have been repeated within a few days, so for some locations two mean values in box 1 and box 2 exist. For the Mauritanian upwelling, $\delta^{3} \mathrm{He}$ within box 1 reaches the equilibrium value of $-1.6 \%$ at about $17^{\circ} \mathrm{W}$ for both cruises. However, during M68/3 further west at some stations an oversaturated mixed layer concentration of helium-3 has been observed, indicating upwelling also at those offshore locations.

\section{Results and discussion}

\subsection{Helium-derived upwelling velocities}

The upwelling velocities calculated according to Eq. (1) are shown in Fig. 3 for all four cruises. Negative values of $w$ are set to zero, so possible downwelling is not considered here. Small differences $C_{1}-C_{2}$ in the denominator of Eq. (1) result in large upwelling velocities. In order to guarantee that such high vertical velocities are not the consequence of uncertainties in the helium measurement, values for $w$ from Eq. (1) are discarded if the absolute value $\left|C_{1}-C_{2}\right|$ is smaller than the quadratic sum of the uncertainties of $C_{1}$ and $C_{2}$, both numbers are assumed to be $0.2 \%$ in $\delta^{3} \mathrm{He}$ units (see next subsection and Table 1).

Overall, at about $60 \%$ of the stations with $\delta^{3} \mathrm{He}$ measurements in the mixed-layer upwelling occurs (26 out of 49 stations for M91 and 43 out of 74 for the Mauritanian cruises). The resulting vertical velocities are of the order of 
Table 1. Error estimation.

\begin{tabular}{lrrrrr}
\hline & $\delta^{3} \mathrm{He}$ box 1 & $\delta^{3} \mathrm{He}$ box 2 & Vert. mixing & Piston velocity $v_{\mathrm{g}}$ & Total \\
\hline Uncertainty & $\pm 0.2 \%$ & $\pm 0.2 \%$ & factor of 2 & $30 \%$ & \\
\hline Error of $w_{\mathrm{He}}$ Peru & $\pm 22 \%$ & $\pm 17 \%$ & $\pm 42 \%$ & $\pm 46 \%$ & $\pm 68 \%$ \\
Error of $w_{\mathrm{He}}$ Maur. & $\pm 42 \%$ & $\pm 26 \%$ & $\pm 64 \%$ & $\pm 59 \%$ & $\pm 100 \%$ \\
\hline
\end{tabular}
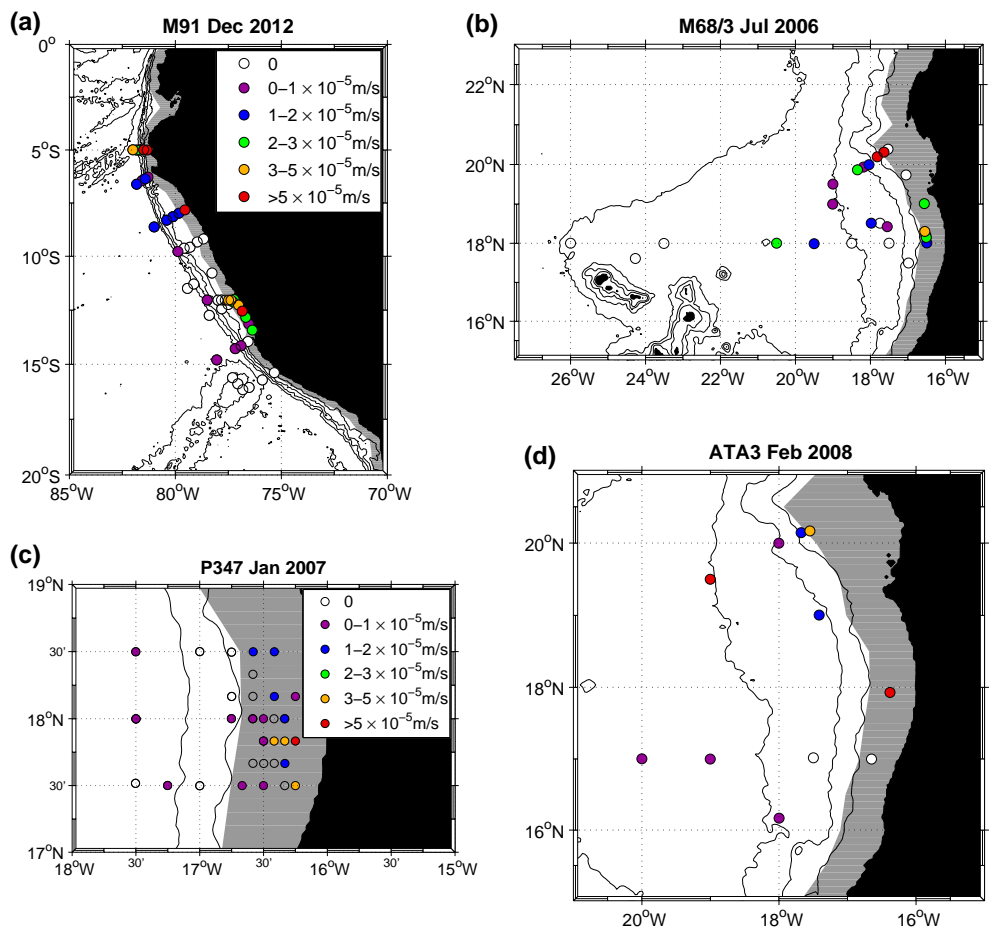

Figure 3. Helium-derived upwelling velocities for cruise M91 off Peru (a) and for cruises M68/3, P347 and ATA3 off Mauritania (b-d). Isobaths are drawn every $1000 \mathrm{~m}$, and the area of the "coastal region" is shaded grey. Note that the uncertainty of the pointwise helium-derived upwelling velocities is $68 \%$ for the Peruvian and $100 \%$ for the Mauritanian data (for details, see text).

$10^{-5} \mathrm{~m} \mathrm{~s}^{-1}$ both for the Peruvian and for the Mauritanian regions.

Off Peru, regions of strong coastal upwelling are found in the northern area between 5 and $8^{\circ} \mathrm{S}$. Another region with high vertical velocities further south at $12-14^{\circ} \mathrm{S}$ is restricted to the coast. Around $10^{\circ} \mathrm{S}$ and south of $15^{\circ} \mathrm{S}$ the upwelling is weak or even vanishing.

The three cruises off Mauritania have a different regional extension. Cruise P347 is restricted to the coast, but with a very dense station spacing. The maximum of the upwelling is located south of $18^{\circ} \mathrm{N}$ near the coast onshore of the $500 \mathrm{~m}$ isobath. The other two cruises which cover a larger area (M68/3 and ATA3) show that the upwelling near the coasts persists up to $20^{\circ} \mathrm{N}$ near Cape Blanc. For these cruises, also at some locations west of $18^{\circ} \mathrm{W}$ enhanced upwelling is observed. Combining the results from the three cruises from the Mauritanian region, the whole picture is that in offshore di- rection the vertical velocity first decreases and then increases again at some locations.

\section{Error estimation}

The total error of the upwelling velocities is computed from the error of the single terms in Eq. (1). This comprises the helium values in boxes 1 and $2, C_{1}, C_{2}$, the gas exchange and the vertical mixing. The ${ }^{3} \mathrm{He} /{ }^{4} \mathrm{He}$ ratio measured at the Bremen high-resolution mass spectrometer has a precision better than $0.4 \%$. The standard deviation of duplicate samples of the cruises presented here is even smaller, about $0.3 \%$. This error of the ${ }^{3} \mathrm{He} /{ }^{4} \mathrm{He}$ ratio is directly linked to the uncertainty of $C_{1}$, the ${ }^{3} \mathrm{He} /{ }^{4} \mathrm{He}$ ratio in the mixed layer. The number $n_{1}$ of samples from the mixed layer for a single profile, where $C_{1}$ is derived from, varies between 1 and 3 . So the uncertainty of $C_{1}$ is $0.3 \% / \sqrt{n_{1}} \approx 0.2 \%$. 
Below the mixed layer, again 1-3 helium measurements leave its mark for the calculation of $C_{2}$. Thus, the error of $C_{2}$ is also about $0.2 \%$.

Another topic is the depth range that is chosen for the calculation of $C_{2}$. The concentration of ${ }^{3} \mathrm{He}$ is typically increasing with depth, so a deeper depth range for calculating $C_{2}$ would lead to smaller upwelling velocities. This effect is partially compensated by the diffusive term, as vertical mixing below the mixed layer often decreases with depth, but in most cases the effect of a depth increase of $C_{2}$ will dominate. This is in agreement with Kadko and Johns (2011), who postulate a decrease of the upwelling velocity with depth. As noted in Tanhua and Liu (2015), the upwelling velocities are valid only for the depth where $C_{2}$ is calculated, which is $5-25 \mathrm{~m}$ below the mixed layer in our case.

The relative standard deviations of $K_{\mathrm{V}}$ for deep and shallow regions is about $100 \%$. Compared to this large value, the error of the vertical helium-3 gradient can be neglected, so the vertical mixing is estimated to vary by a factor of 2 from the calculated value.

For the gas exchange, an error of $30 \%$ for the piston velocity is assumed. This error comprises both variations in wind speed over the equilibrium timescale for the gas exchange (see above) and errors in the parameterization of the piston velocity. All these errors are listed in Table 1.

The influence of the errors of the input values on the upwelling velocity $w$ is non-linear (see Eq. 1). Thus the upwelling velocities are calculated for adding and subtracting the errors from the input values. In this way, a minimum and a maximum upwelling velocity is computed, and the error is assumed to be half of the difference. This is done for each source of error separately. In the Peruvian upwelling, both surface as well as subsurface helium-3 concentrations are much higher than off Mauritania (Figs. 1 and 2). Thus, the "signal to noise ratio" of $C_{1}$ and $C_{2}$ is larger for the region off Peru, and the error estimation is done separately for both upwelling regions.

The relative errors of $w$ for each source of error are shown in Table 1. Although the uncertainty of $C_{1}$ and $C_{2}$ is the same, the resulting error in the upwelling velocity $w$ is much larger for $C_{1}$ than for $C_{2}$. This is because $C_{1}$ appears in Eq. (1) not only in the nominator $\left(C_{1}-C_{2}\right)$, but also influences the magnitude of the gas exchange in the nominator of Eq. (1). A change of $C_{1}$ in one direction causes a change of $w$ in the same direction for both terms.

As was expected, the better signal to noise ratio of $C_{1}$ and $C_{2}$ for the Peruvian area results in a smaller error for $w$ compared to the Mauritanian region. Also the uncertainty of $w$ resulting from the diapycnal mixing and the piston velocity is smaller for the Peruvian region. Note that the uncertainty of $w$ due to vertical mixing is much smaller than the error of the mixing itself, as in many cases the term for the vertical diffusion in Eq. (1) is small compared to the gas exchange term. The total error calculated as the quadratic sum of the four error terms of the inferred upwelling velocity is $68 \%$ off Peru and $100 \%$ off Mauritania.

\subsection{Comparison between helium- and wind-derived upwelling}

We will now compare the upwelling velocities derived from the helium method ( $\left.w_{\text {Helium }}\right)$ with those calculated directly from the wind field ( $\left.w_{\text {Wind }}\right)$. In the open ocean away from coastal boundaries, the upwelling velocity at the base of the Ekman layer can be computed directly from the wind stress curl (see e.g. Gill, 1982)

$w=\frac{1}{\rho}\left(\frac{\partial}{\partial x}\left(\frac{\tau_{y}}{f}\right)-\frac{\partial}{\partial y}\left(\frac{\tau_{x}}{f}\right)\right)$,

with water density $\rho$, Coriolis parameter $f$ and the zonal and meridional components of the wind stress $\tau_{x}$ and $\tau_{y}$. Near the coast, the lateral boundary is taken into account using a twolayer model (Yoshida, 1955). The solutions for the velocity $u$ in the upper layer directed offshore and the vertical velocity $w$ have the form (Gill, 1982):

$u=-\frac{\tau_{y}}{\rho f H_{1}}\left(1-e^{-x / a}\right)$

$w=\frac{\tau_{y}}{\rho f a} e^{-x / a}$.

$H_{1}$ is the depth of the upper layer (Ekman layer), and $\tau_{y}$ denotes the wind stress component parallel to the coast. The spatial scale of the upwelling area is given by the first internal Rossby radius $a$. $a$ is calculated for a two layer ocean with densities $\rho_{1}$ and $\rho_{2} . \rho_{1}$ is the density of the mixed layer. For $\rho_{2}$ we have chosen the mean density between the lower boundary of the mixed layer and $500 \mathrm{~m}$ depth, which is approximately the lower boundary of the central water from which the upwelled water originates. For each of the three cruises, a mean value of $a$ is calculated, as the stratification and thus the Rossby radius between the cruises might differ. The resulting values are $a=15 \mathrm{~km}$ for M91, $a=16 \mathrm{~km}$ for M68/3, $a=10 \mathrm{~km}$ for P347 and $a=12 \mathrm{~km}$ for ATA3. The magnitude of the wind-driven coastal upwelling velocities at each station depends on the choice of the Rossby radius $a$ in Eq. (6). The total vertical transport integrated over the coastal area, i.e. a distance of several Rossby radii, is almost independent from $a$. The alongshore velocity (coastal jet) in Eq. (5) increases linearly with time, so this solution does not represent a steady state. More complex solutions can be found (Fennel, 1999) where the increase of the coastal jet is limited due to the generation of coastal trapped Kelvin waves.

$x$ in Eqs. (5) and (6) denotes the distance from the coast. The continental shelf in the study area is relatively broad, and the mixed layer in this region has a mean depth of 10-25 m. The upwelled water has to be supplied from below the mixed layer, but this is only possible if the water depth is considerably larger than the mixed layer (more correct: Ekman layer) 
depth itself. We thus assume a minimum water depth of $50 \mathrm{~m}$ (two times the mixed layer depth) for wind-driven upwelling to occur and set $x$ as the distance from the $50 \mathrm{~m}$ isobath. In this case, $w_{\text {Wind }}$ calculated according to Eq. (6) is comparable in magnitude with $w_{\text {Helium }}$ (Fig. 4a). Setting $x=0$ directly at the coast leads to $w_{\text {Wind }}$ being 1 order of magnitude smaller. As wind-driven vertical velocity $w_{\text {wind }}$ which has to be compared with $w_{\text {Helium }}$ we choose the maximum value of both calculations according to Eqs. (4) and (6), which means that either the influence of the coastal boundary is dominating the vertical Ekman velocity or the wind stress curl over the open ocean.

$w_{\text {Wind }}$ is calculated from the gridded daily wind data which are interpolated onto the station locations in the same way as for calculating the gas exchange velocity. Also for $w_{\text {Wind }}$ the temporal mean over the period that is given by the gas exchange timescale ( $n$ days, see Sect. 3 ) is taken. So $w_{\text {Wind }}$ covers the same timescale of $n$ days as $w_{\text {Helium. }}$. Nevertheless, there is a difference in the interpretation of the temporal mean of $w_{\text {Wind }}$ and $w_{\text {Helium }}$. Whereas $w_{\text {Helium }}$ has to be interpreted as the Lagrangian mean following the patch of surface water, $w_{\text {Wind }}$ is the Eulerian mean. Another difference between $w_{\text {Wind }}$ and $w_{\text {Helium }}$ is the fact that $w_{\text {Helium }}$ strictly speaking describes the entrainment velocity: $w_{\text {Helium }}=w_{\text {Wind }}-\partial z_{\text {mld }} / \partial t$. Here, $z_{\text {mld }}$ denotes the lower boundary of the mixed layer.

To overcome the difference between these methodological differences and also to reduce the large error of the pointwise $w_{\text {Helium }}$ data, regional mean values of $w_{\text {Wind }}$ and $w_{\text {Helium }}$ are calculated. For these mean values, the differences between Eulerian and Lagrangian mean as well as between vertical and entrainment velocity should be reduced. The regions are the area within the $50 \mathrm{~km}$ distance to the $50 \mathrm{~m}$ isobath, where the boundary solution from Eq. (6) is typically larger than the open ocean result from Eq. (4), all stations with larger distance from the coast make up the other region. These areas will be referred to as "coastal", and "offshore" respectively. The error of the regional mean values of $w_{\text {Wind }}$ and $w_{\text {Helium }}$ is the standard deviation of the pointwise velocity data within the region with helium data divided by the square-root of the number of those stations. For the helium-derived upwelling, this error is typically larger than dividing the $100 \%$ error of the single measurements by the square root of the number of data points. The reason is that vertical velocities in one region are varying by up to an order of magnitude.

All mean values for the coastal and offshore regions for each cruise are given in Table 2 and represented graphically in Fig. 4. For the coastal regions, mean upwelling velocities are of the order of $10^{-5} \mathrm{~m} \mathrm{~s}^{-1}$, whereas for the offshore regions they vary between $10^{-5} \mathrm{~m} \mathrm{~s}^{-1}$ and only $10^{-6} \mathrm{~m} \mathrm{~s}^{-1}$. The coastal values for $w_{\text {Helium }}$ and $w_{\text {Wind }}$ off Mauritania agree for all three cruises within their error bars. The winter cruise $\mathrm{P} 347$ shows the smallest coastal upwelling $1.4 \pm 0.4 \times 10^{-5} \mathrm{~m} \mathrm{~s}^{-1}$. The other winter cruise ATA3 and also the summer cruise M68/3 have larger values $2.1 \pm 0.8 \times$
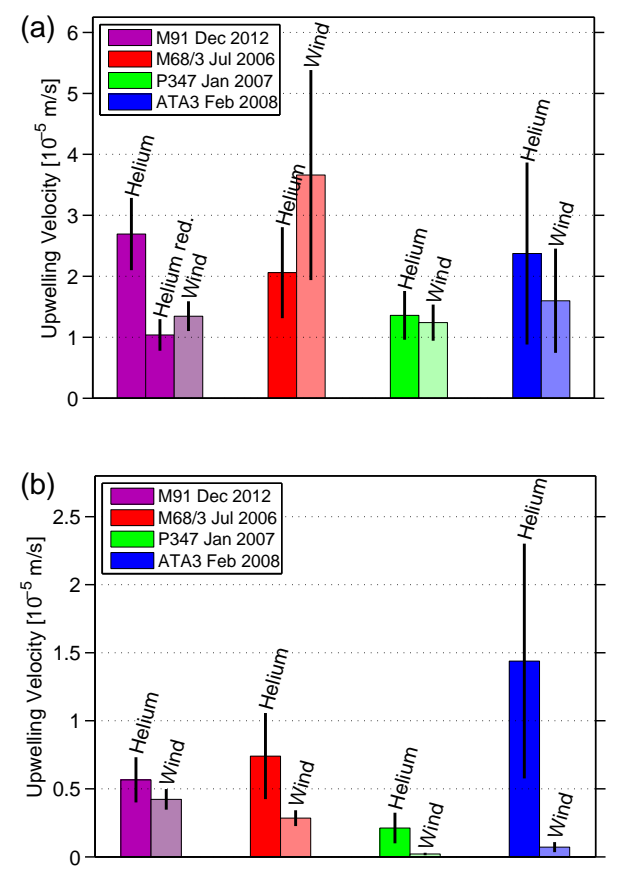

Figure 4. Mean values of helium- and wind-derived upwelling velocities for the coastal (a) and offshore (b) areas of cruises M91, M68/3, P347 and ATA3. The vertical black line indicates the standard deviation of the mean. "Helium red" in (a) means that the helium-derived upwelling is calculated with reduced gas exchange velocity due to the presence of surface organic films, for details see text.

$10^{-5}-2.4 \pm 1.5 \times 10^{-5} \mathrm{~m} \mathrm{~s}^{-1}$. These numbers, however, agree within their error bars. This implies that no seasonal variation of the upwelling has been observed, but the limited number of three cruises might not be representative for the respective season. Offshore, only for cruise P347 $w_{\text {Helium }}$ is small $\left(0.2 \times 10^{-5} \mathrm{~m} \mathrm{~s}^{-1}\right)$. For all Mauritanian cruises $w_{\text {Helium }}$ surpasses $w_{\text {Wind }}$ in the offshore region.

For the Peruvian area, the differences between $w_{\text {Helium }}$ and $w_{\text {Wind }}$ show an opposite behaviour: they are relatively small for the offshore region, but large for the coastal area $(\approx$ $1.1 \times 10^{-5} \mathrm{~m} \mathrm{~s}^{-1}$ for $w_{\text {Wind }}$ in contrast to $\approx 2.7 \times 10^{-5} \mathrm{~m} \mathrm{~s}^{-1}$ for $\left.w_{\text {Helium }}\right)$. One reason for the high value of $w_{\text {Helium might }}$ be an overestimation of the gas exchange velocity in Eq. (3) due to the presence of organic surface films (surfactants). These films have been observed on cruise M91, and their damping behaviour on surface waves have been shown in Kiefhaber et al. (2015). There, the observed mean square slope of the waves was found to be overestimated by the parameterization for clean water. Most measurements are in the range spanned by clean water and slick parameterizations. Surfactants also drastically reduce the transport of gases across the water surface. A parameterization of the gas transfer velocity in the presence of surfactant is given in Tsai and Liu (2003). However, there the gas transfer for the case with and without surface films are based on the parameteri- 
Table 2. Mean upwelling velocities $w$.

\begin{tabular}{|c|c|c|c|c|c|c|c|c|c|}
\hline & \multicolumn{3}{|c|}{ M91 } & \multicolumn{2}{|c|}{ M68/3 } & \multicolumn{2}{|c|}{ P347 } & \multicolumn{2}{|c|}{ ATA3 } \\
\hline & coastal & coastal surf. & offshore & coastal & offshore & coastal & offshore & coastal & offshore \\
\hline$\sharp$ prof. $w>0$ & 14 & 12 & 12 & 5 & 8 & 17 & 4 & 2 & 7 \\
\hline$\sharp$ prof. $w \leq 0$ & 5 & 7 & 18 & 3 & 9 & 11 & 6 & 1 & 1 \\
\hline$w_{\text {Helium }}\left[10^{-5} \mathrm{~ms}^{-1}\right]$ & $2.7 \pm 0.6$ & $1.0 \pm 0.3$ & $0.6 \pm 0.2$ & $2.1 \pm 0.7$ & $0.7 \pm 0.3$ & $1.4 \pm 0.4$ & $0.2 \pm 0.1$ & $2.4 \pm 1.5$ & $1.4 \pm 0.9$ \\
\hline$w_{\text {Wind }}\left[10^{-5} \mathrm{~ms}^{-1}\right]$ & $1.3 \pm 0.2$ & - & $0.4 \pm 0.1$ & $3.7 \pm 1.7$ & $0.3 \pm 0.1$ & $1.2 \pm 0.3$ & $0.02 \pm 0.01$ & $1.6 \pm 0.9$ & $0.07 \pm 0.04$ \\
\hline
\end{tabular}

zation form Liss and Merlivat (1986). For low wind speeds as have been prevailing during cruise M91, this formula results in smaller gas transfer velocities than Eq. (3) even for the normal case without surfactants. Including the reduction factor $r$ from Tsai and Liu (2003) $\left(r=0.56 \mathrm{U}_{10}^{-0.13}\right)$ for the case with surfactant, the resulting gas exchange and thus the helium-derived vertical velocities would almost vanish. We thus adopt the reduction factor from Tsai and Liu (2003), but apply it to the gas transfer velocity from Nightingale et al. (2000), Eq. (3). The resulting mean upwelling velocity for the coastal area is also given in Table 2 and Fig. $4 \mathrm{a}$ and is in good agreement with the wind-derived value $w_{\text {Wind }}$. Figure 5 shows the distribution $w_{\text {Helium }}$ for the case of the reduced gas transfer velocity. Comparison with Fig. 3a for the standard gas exchange shows that the overall pattern of the distribution of the vertical velocities remains unchanged, only the coastal values are smaller. In Kiefhaber et al. (2015) not all data points are influenced by surfactants. As illustrated in Fig. 4a, the helium-derived upwelling velocity based on reduced gas exchange at all coastal stations is slightly smaller than the wind-derived one, indicating that the effect of surfactants is overestimated when being applied to all stations.

One could argue that the enhanced $\delta^{3} \mathrm{He}$ values in the offshore region are the remnants from helium-3 rich water originating in the coastal upwelling and then have being advected offshore. Taking into account the equilibrium timescale for the helium gas exchange, after about 20 days the mixed-layer disequilibrium of helium-3 should have decreased to about $10 \%$ of the value from the upwelled water $(<0.1 \%$ for the Mauritanian and $<0.2 \%$ for the Peruvian upwelling). Assuming an advection velocity of $\approx 10 \mathrm{~cm} \mathrm{~s}^{-1}$ in offshore direction, the water could move about $200 \mathrm{~km}$ away from the coast over the 20-day time period. For the Peruvian area, most stations are within this distance, so an influence from the coastal upwelling on the offshore helium-3 values cannot be excluded. For the Mauritanian region, enhanced $\delta^{3} \mathrm{He}$ values can be found even west of $18^{\circ} \mathrm{W}$, too far west to be remnants from the coastal upwelling. Possible explanations for the large offshore vertical velocities will be given below.

\subsection{Other upwelling mechanisms}

The discrepancies between the wind- and helium-derived upwelling velocities especially in the offshore region suggest the existence of additional upwelling mechanisms. These

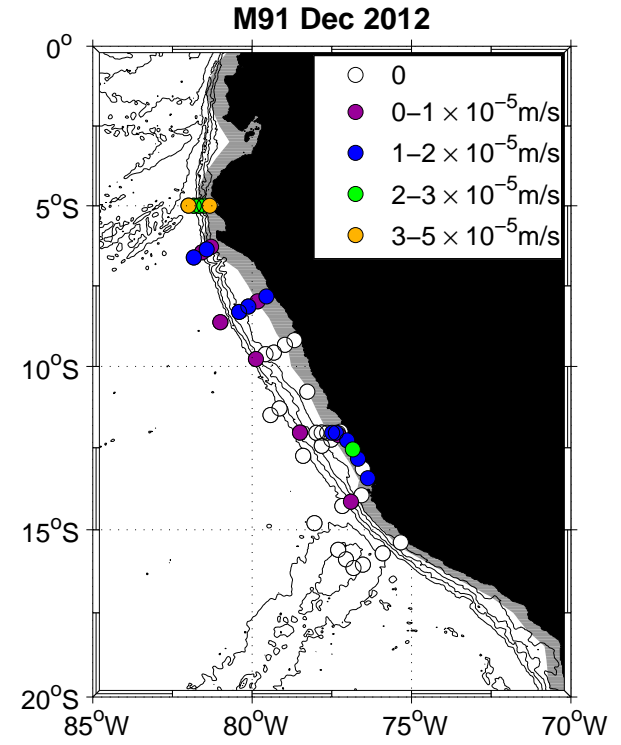

Figure 5. Helium-derived vertical velocity for cruise M91. As in Fig. 3a, but applying a reduced gas transfer velocity in the coastal area due to the presence of surface films.

would be included in the helium-derived vertical velocities, but not in the purely wind-driven ones. For the region at the Mauritanian coast, large helium-derived velocities for cruises M68/3 and ATA3 are located south of Cape Blanc near $20^{\circ} \mathrm{N}$ (Fig. $3 \mathrm{~b}$ and d). These maxima do not show corresponding high values in the wind-driven upwelling. Mazzini and Barth (2013) concluded from a model study that flowtopography interaction is upwelling favourable downstream of capes, a situation which is given south of Cape Blanc following the south westward direction of the Canary Current. Thus in this case the wind-derived vertical velocity might be an underestimation.

Another explanation for the high vertical velocities from the helium method which surpass the Ekman derived values by up to 1 order of magnitude is eddy-induced upwelling. Several mechanisms for this phenomenon are possible: uplift of isopycnals close to the mixed layer, as they occur in cyclones and mode water eddies. Stramma et al. (2013) observed subsurface chlorophyll maxima in such types of eddies in the Peruvian upwelling on cruise M90, just 1 month prior to the cruise M91 discussed here, and ascribed them to 


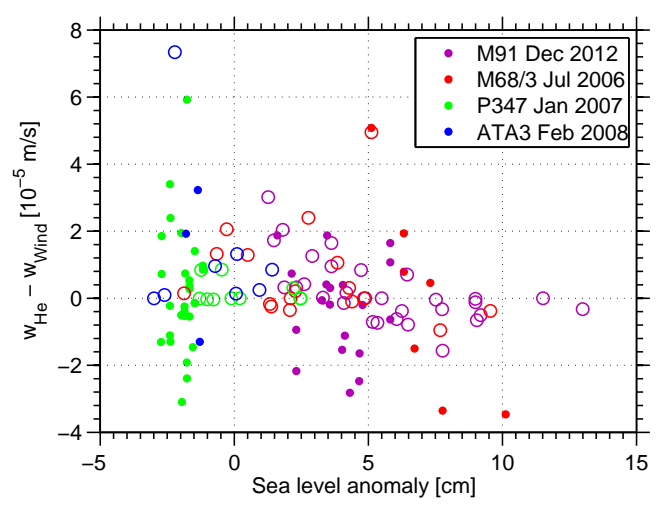

Figure 6. Difference between helium- and wind-derived vertical velocity against sea level anomaly at each station for the coastal (filled circles) and offshore (open circles) region of cruises M91, M68/3, P347 and ATA3. Note that the uncertainty of the helium-derived upwelling velocities is $68 \%$ for the Peruvian and $100 \%$ for the Mauritanian data.

this mechanism. The helium method is however not able to catch this process as long as the uplifting of isopycnals does not lead to an intrusion of subsurface water into the mixed layer. In the opposite direction, when the upwelled water leaves the coastal area, the mixed layer might deepen, leading to entrainment of water from below. This process would be classified as upwelling by the helium method. However, no correlation between enhanced offshore upwelling and deep mixed layers can be found from the data off Mauritania.

Ekman suction due to wind stress on the eddy is also suggested to foster upwelling (Martin and Richards, 2001). Here, at the side of the eddy where the eddy flow is in the same direction as the wind, the wind stress is reduced, whereas it is enhanced on the opposite side of the eddy, where wind and eddy flow are in the opposite direction. This difference in wind stress between both sides of the eddy induce an upwelling for anticyclones and mode water eddies and a downwelling for cyclones. Another mechanisms also described in Martin and Richards (2001) is upwelling by ageostrophic circulation resulting from a perturbation of the eddy flow field.

In order to investigate a possible influence of eddies on the helium-derived upwelling velocity, the gridded AVISO sea level anomaly (SLA) has been interpolated on the station location. Figure 6 shows the interpolated SLA against $\Delta w=w_{\text {Helium }}-w_{\text {Wind }}$, i.e. the portion of the vertical velocity, which is not explained by wind-driven upwelling. For the coastal data, no relation between SLA and $\Delta w$ can be found. For the offshore data, towards the centre of anticyclones (SLA $>5 \mathrm{~cm}$ ), the upwelling is slightly reduced. At offshore points with smaller SLA $(5 \mathrm{~cm}>$ SLA $>-5 \mathrm{~cm})$, $\Delta w$ is either positive or close to zero. If the two data points with $w_{\text {Helium }}>4 \times 10^{-5} \mathrm{~m} \mathrm{~s}^{-1}$ are regarded as outliers, the offshore data form a triangular pattern with the edges at $\left[-4 \mathrm{~cm} / 0 \mathrm{~m} \mathrm{~s}^{-1}\right],\left[1 \mathrm{~cm} / 3 \times 10^{-5} \mathrm{~m} \mathrm{~s}^{-1}\right]$ and $\left[5 \mathrm{~cm} / 0 \mathrm{~m} \mathrm{~s}^{-1}\right]$.
The eddy-wind interaction can thus be ruled out as mechanisms responsible for the upwelling, as this only works for positive SLA. Another reason is that even in that case, for the moderate wind speeds observed during all cruises $\left(u_{10}<\right.$ $10 \mathrm{~m} \mathrm{~s}^{-1}$ ), the resulting upwelling would only be of the order of $10^{-6} \mathrm{~m} \mathrm{~s}^{-1}$. A strong upwelling of order $10^{-5} \mathrm{~m} \mathrm{~s}^{-1}$ as observed by McGillicuddy Jr. et al. (2007) only occurs for high windspeeds $\left(u_{10}>10 \mathrm{~m} \mathrm{~s}^{-1}\right)$.

The spatial distribution of SLA and $\Delta w$ at the offshore data points is shown in Fig. 7 for each cruise. Whereas in Fig. 6 weekly means are used for SLA, in Fig. 7 the mean from the weekly SLA over the duration of the cruises is shown in order to get only one map per cruise and thus a comprehensive picture. Figure 7 illustrates that enhanced upwelling occurs at the edge of eddies at locations of small SLA. These enhanced vertical velocities are, however, not a general feature of eddy boundaries. We conclude that ageostrophic instabilities that might occur at the edge of eddies are the main mechanism for eddy-induced upwelling. On the other hand, towards the centre of anticyclones upwelling is weakened.

\subsection{Nutrient fluxes}

The coastal regions off Peru and Mauritania belong to the most productive areas of the world ocean. We thus consider the relation between nutrient supply into the mixed layer from vertical transports (both advective and diffusive) and net primary production (NPP) observed from satellites (http://www.science.oregonstate.edu/ocean. productivity/index.php). The advective and diffusive phosphate fluxes into the mixed layer are computed in the same way as the helium-3 flux: the concentration of phosphate in box $2\left(C_{2}\right)$, the phosphate gradient and the vertical diffusivity are calculated as vertical mean over the depth range 5-25 m below the mixed layer. If no microstructure data are available, the diffusion coefficient is set to the regional mean (see Sect. 3). As advective velocities in the Peruvian upwelling $w_{\text {Helium }}$ derived from the reduced gas exchange is used, these values are in better agreement with $w_{\text {Wind }}$.

Similar to the SLA data, the 8 day mean values of satellitederived productivity are interpolated on the station locations. In order to allow for a reaction of the productivity to changes in nutrient supply, the productivity data are shifted in time by half a week. For a quantitative comparison between NPP and phosphate fluxes, the latter are converted to carbon units by multiplying with the Redfield ratio of 117 from Anderson and Sarmiento (1994).

The spatial distribution of NPP and vertical carbon transport is shown in Fig. 8 for each cruise. As for SLA, the NPP values over the time period of each cruise are averaged to get one comprehensive map per cruise. Here, at least a qualitative correlation between NPP and carbon flux can be observed. At the northern end of the Peruvian area, e.g. enhanced carbon fluxes reach from the onshore up to the offshore end of the 

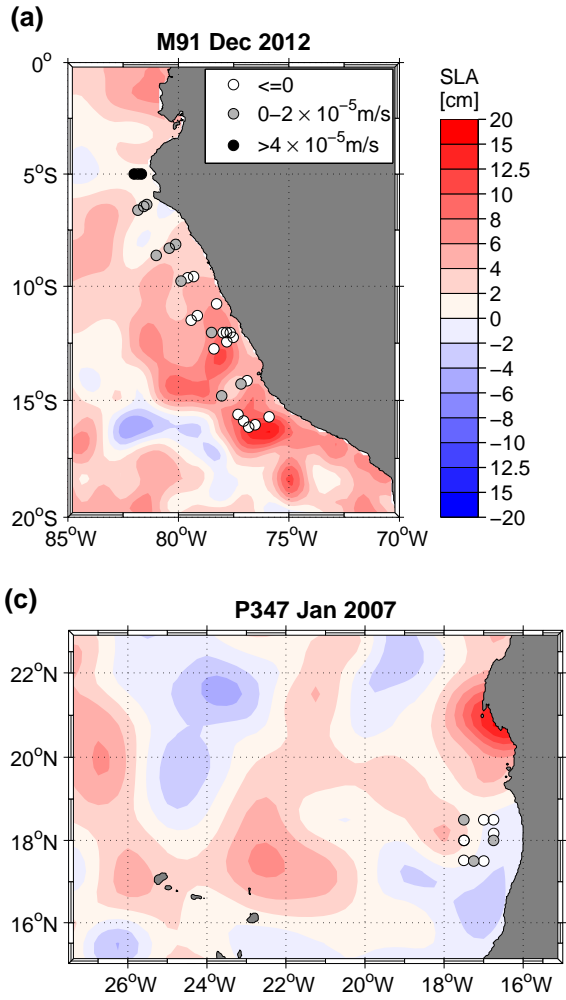

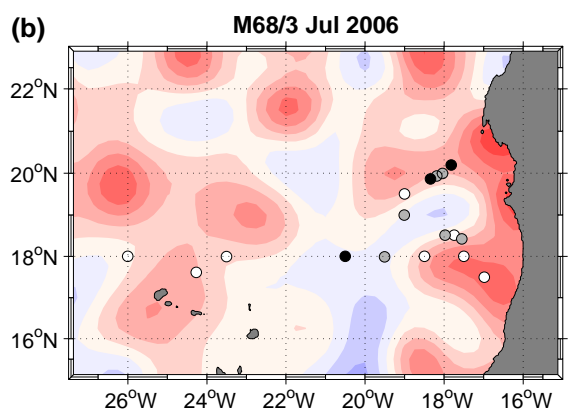

(d)

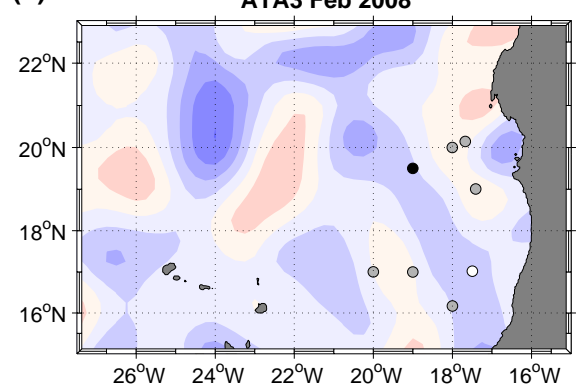

Figure 7. Mean sea level anomaly over the time period of the respective cruise for M91 (a), M68/3 (b), P347 (c), and ATA3 (d). The difference between helium- and wind-derived vertical velocity is indicated by the grey dots. For details see text.

sections, and the area with enhanced NPP also stretches relatively far offshore in this northern area. For cruise M68/3, the offshore area with striking high NPP around $20^{\circ} \mathrm{W}$ might be fostered by the relatively large vertical nutrient transport observed at the two stations near $19^{\circ} \mathrm{W}$. The reason for the high nutrient fluxes at this location is the above-mentioned eddyinduced upwelling. The stations near $18^{\circ} \mathrm{W}, 16.5^{\circ} \mathrm{N}$ are at least in close vicinity to the area with high NPP along the coast. For cruise P347 the calculated nutrient-carbon fluxes reflect the decrease of NPP in offshore direction. The limited number of stations with nutrient fluxes for ATA3 hamper to find a correlation with the underlying NPP field.

The spatial misfit between NPP and vertical nutrient supply might also be due to the temporal delay between them. Over this delay time, the upwelled water is advected horizontally, so NPP and nutrient flux are not expected to appear exactly at the same location. The lack of correlation between upwelling (local forcing) and primary production has also been found in a study by Carr and Kearns (2003). They analysed the governing factors for the biological production in eastern boundary current systems and found even negative correlations between local forcing and primary production both for the northern part of the Humboldt Current off Peru $\left(5-15^{\circ} \mathrm{S}\right)$ and the southern part of the Canary Current off Mauritania $\left(11^{\circ} \mathrm{S}-20^{\circ} \mathrm{N}\right)$ (Carr and Kearns, 2003, Table 3).
The important parameter for primary production is the nutrient flux at the base of the euphotic zone. However, neither the depth of the euphotic zone nor the vertical velocity $w$ at this location is precisely known. Typically, the euphotic zone is deeper than the relatively shallow mixed layers observed in the upwelling regions. Assuming a decrease of $w$ with depth and an increase of nutrient concentrations, these two gradients are counteracting in their effect on the nutrient flux, so the numbers presented here are considered as approximations of the nutrient flux in the euphotic zone.

Values for NCP in the Peruvian and Mauritanian upwelling have been calculated by Minas et al. (1986), $0.59 \mathrm{~g} \mathrm{C} \mathrm{m}^{-2} \mathrm{~d}^{-1}$ off Peru and $2.51 \mathrm{~g} \mathrm{C} \mathrm{m}^{-2} \mathrm{~d}^{-1}$ off Mauritania. For comparison, the regional mean values of the vertical carbon fluxes from this study are given in Table 3, divided into a diffusive and an advective part. As in Minas et al. (1986), the value for the Peruvian upwelling is smaller than for Mauritania (1.3 vs. $1.6-2.1 \mathrm{~g} \mathrm{C} \mathrm{m}^{-2} \mathrm{~d}^{-1}$ ), but the difference is much less pronounced.

The nutrient fluxes into the mixed layer by vertical advection and vertical mixing are of similar magnitude for the Peruvian offshore area and in most cases both for the coastal and offshore region off Mauritania. Over the Mauritanian shelf break, the vertical diffusivity is largely enhanced due to tide-topography interactions (Schafstall et al., 2010), which explains the high diffusive fluxes. Our result of 0.8 
(a)
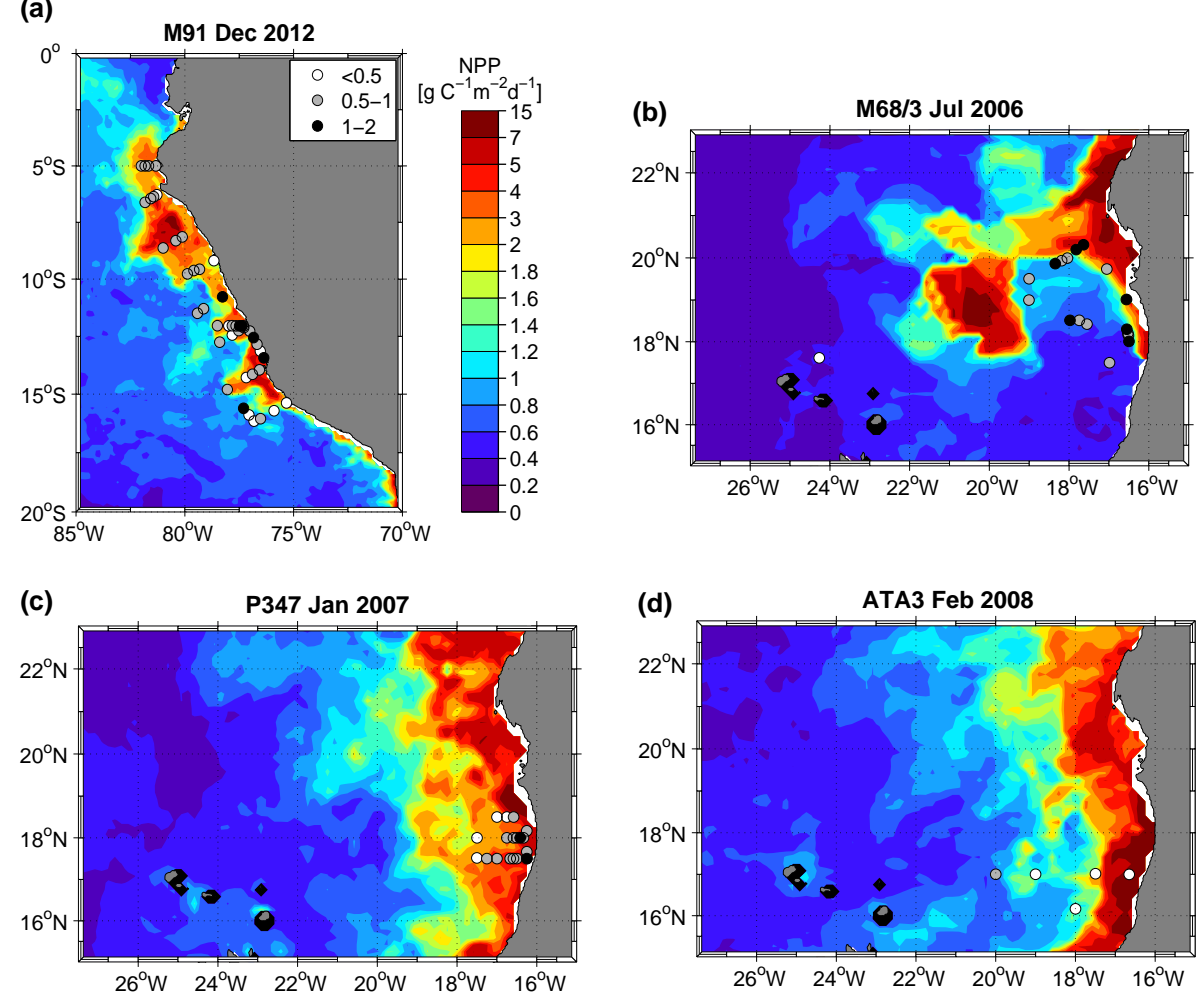

Figure 8. Mean net primary production over the time period of the respective cruise for M91 (a), M68/3 (b), P347 (c), and ATA3 (d). The vertical phosphate transport (advective plus diffusive part) into the mixed layer is converted to carbon units by the Redfield ratio and indicated by the grey dots. Note that the error of these fluxes is $100 \%$. For details see text.

Table 3. Mean advective, diffusive, and total $\mathrm{PO}_{4}$ fluxes into the mixed layer converted to carbon units [ $\mathrm{g} \mathrm{C} \mathrm{m}^{-2} \mathrm{~d}^{-1}$ ] via the Redfield ratio.

\begin{tabular}{|c|c|c|c|c|c|c|c|c|}
\hline & \multicolumn{2}{|c|}{ M91 } & \multicolumn{2}{|c|}{ M68/3 } & \multicolumn{2}{|c|}{ P347 } & \multicolumn{2}{|c|}{ ATA3 } \\
\hline & coastal & offshore & coastal & offshore & coastal & offshore & coastal & offshore \\
\hline adv. & $1.0 \pm 0.3$ & $0.4 \pm 0.1$ & $1.1 \pm 0.4$ & $0.7 \pm 0.3$ & $0.8 \pm 0.3$ & $0.2 \pm 0.1$ & - & $0.4 \pm 0.3$ \\
\hline diff. & $0.3 \pm 0.1$ & $0.5 \pm 0.1$ & $0.9 \pm 0.2$ & $0.9 \pm 0.2$ & $0.8 \pm 0.4$ & $0.2 \pm 0.1$ & $0.9 \pm 0.3$ & $0.08 \pm 0.03$ \\
\hline total & $1.3 \pm 0.3$ & $0.9 \pm 0.1$ & $2.1 \pm 0.5$ & $1.6 \pm 0.4$ & $1.6 \pm 0.5$ & $0.4 \pm 0.1$ & - & $0.5 \pm 0.3$ \\
\hline
\end{tabular}

For cruise ATA3, no advective nutrient flux for the coastal area has been computed. Only one station with helium and phosphate data for that regions is available, which is not sufficient to calculate a mean value.

$0.9 \mathrm{~g} \mathrm{C} \mathrm{m}^{-2} \mathrm{~d}^{-1}$ is almost identical with the study in Schafstall et al. (2010) for the same region, but not exactly the same subset of cruises. Further offshore, the vertical diffusivity drops by more than 1 order of magnitude, which is not compensated by the slightly larger subsurface increase of nutrients in the offshore areas (Fig. 2d-f). This is different for the Peruvian region, where coastal and offshore diffusivities reach the same magnitude at some stations. Here, the diffusive flux offshore is even higher than near the coast, and the coastal flux is dominated by the advective contribution. According to Carr and Kearns (2003), the open ocean productivity is reduced by a factor of 10 compared to the coastal upwelling areas. Such small values of vertical nu- trient transport have been found in Haskell II et al. (2015) further offshore off Peru $\left(0.01-0.1 \mathrm{~g} \mathrm{C} \mathrm{m}^{-2} \mathrm{~d}^{-1}\right)$. This indicates the transition from the upwelling regime towards the oligotrophic subtropical gyre. In the offshore regions adjacent to the coastal boundary analysed here, the vertical nutrient transport is also smaller than at the coast, but only by a factor of 1.3 (Peru, cruise M91) to 4 (Mauritania, cruise P347). The offshore filaments of enhanced productivity observed from satellite (Fig. 8) might thus not only be fed by horizontal advection of nutrients out of the coastal zone, but also by nutrient input from below the mixed layer.

The general importance of eddies for the nutrient supply has been shown by Oschlies and Garçon (1998) in a model 
for the Atlantic. In another model study Gruber et al. (2011) show that the presence of eddies reduces the nutrient transport into the euphotic zone and thus the productivity in eastern boundary upwelling systems compared to the noneddying case in the region adjacent to the coast $(0-500 \mathrm{~km})$. Further offshore (500-1000 km), however, the eddy field induces an increase in primary production and carbon export.

\section{Conclusions}

Vertical velocities $w$ for the eastern boundary current upwelling systems off Peru and Mauritania regions have been determined by using the ${ }^{3} \mathrm{He} /{ }^{4} \mathrm{He}$ disequilibrium in surface waters. The mean upwelling velocity over the coastal regions varies between $1.1 \pm 0.3 \times 10^{-5}$ and $2.4 \pm 1.5 \times 10^{-5} \mathrm{~m} \mathrm{~s}^{-1}$ and is similar for both regions. In the equatorial Atlantic Rhein et al. (2010) and Kadko and Johns (2011) found vertical velocities reaching from $0.6 \times 10^{-5}$ to $2.6 \times 10^{-5} \mathrm{~m} \mathrm{~s}^{-1}$. Thus both the equatorial and the coastal upwelling are of similar strength.

For the Mauritanian area, Tanhua and Liu (2015) have calculated upwelling velocities using the same box model as here, but CFC-12 and $\mathrm{SF}_{6}$ as tracers. For a winter and spring cruise, the vertical velocities are between 0 and $11 \times$ $10^{-5} \mathrm{~m} \mathrm{~s}^{-1}$, comparable with our results. For the summer cruise M68/3, Tanhua and Liu (2015) find no indications for upwelling. Their data set, however, only contains a few stations along $18^{\circ} \mathrm{N}$. Our coastal stations along that line also have low vertical velocities (between 0 and $2 \times 10^{-5} \mathrm{~m} \mathrm{~s}^{-1}$ ), whereas directly north and around $20^{\circ} \mathrm{N}$ the helium-derived upwelling exceeds $3 \times 10^{-5} \mathrm{~m} \mathrm{~s}^{-1}$.

Haskell II et al. (2015) investigate upwelling in the Eastern Tropical South Pacific at a few stations based on the ${ }^{7} \mathrm{Be}$ method. Their vertical velocities are also in the order of $10^{-5} \mathrm{~m} \mathrm{~s}^{-1}\left(0-3 \times 10^{-5} \mathrm{~m} \mathrm{~s}^{-1}\right)$, whereby the maximum value of $3 \times 10^{-5} \mathrm{~m} \mathrm{~s}^{-1}$ might be due to "anomalous ${ }^{7} \mathrm{Be}$ measurements".

An independent estimate of the upwelling velocity can be inferred by Ekman theory (Gill, 1982). Near the coast, the agreement between wind- and helium-derived mean vertical velocities is fair, if a "minimum" water depth of $50 \mathrm{~m}$ for upwelling to occur is chosen. For the Peruvian upwelling, the vertical velocity-derived from the helium method in conjunction with the gas exchange parameterization of Nightingale et al. (2000) leads to an overestimation of the upwelling, as the gas exchange is reduced due to the presence of surface surfactants (Kiefhaber et al., 2015). Assuming a reduction of the piston velocity in the whole coastal area off Peru leads to a small underestimation of the upwelling, but helium- and wind-derived values still agree within their errors.

In contrast to the broad agreement between the mean upwelling derived from the helium and the wind method, at greater distances from the Mauritanian coast large discrepancies occur. Here, the helium-derived upwelling still reaches $1 \times 10^{-5} \mathrm{~m} \mathrm{~s}^{-1}$, whereas the wind-driven upwelling from Ekman suction is smaller by up to one order of magnitude. Haskell II et al. (2015) find an upward velocity of $1 \times 10^{-5} \mathrm{~m} \mathrm{~s}^{-1}$ at $10^{\circ} \mathrm{S}, 100^{\circ} \mathrm{W}$, which is another indication for enhanced upwelling in the open ocean. One possible mechanism is eddy-induced upwelling by perturbations of the eddy flow field (Martin and Richards, 2001). This view is supported by sea level anomalies, which are moderate at the locations of maximum upwelling, i.e. the largest upwelling is found at the edge of eddies and not in their centre.

Vertical advection and diapycnal mixing are the most important mechanisms for the transport of substances from the interior ocean into the surface mixed layer. As a consequence, the upwelling regimes belong to the most productive ocean regions. Due to the high vertical diffusivities at the shelf break off Mauritania (Schafstall et al., 2010), in that area the diffusive nutrient flux is of the same magnitude as the advective one. Both types of fluxes together are equivalent to a carbon flux of $1.3 \pm 0.3 \mathrm{~g} \mathrm{C} \mathrm{m}^{-2} \mathrm{~d}^{-1}$ for the Peruvian and $1.6-2.1 \pm 0.5 \mathrm{~g} \mathrm{C} \mathrm{m}^{-2} \mathrm{~d}^{-1}$ for the Mauritanian region. The upwelling also leads to enhanced nutrient fluxes in the offshore region, which can reach up to $1.5 \pm 0.4 \mathrm{~g} \mathrm{C} \mathrm{m}^{-2} \mathrm{~d}^{-1}$ off Mauritania during the cruise M68/3 and $1.0 \pm 0.1 \mathrm{~g} \mathrm{C} \mathrm{m}^{-2} \mathrm{~d}^{-1}$ off Peru for cruise M91.

Acknowledgements. This work is part of the German research project Surface Ocean Processes in the Anthropocene (SOPRAN), funded by the German Federal Ministry of Education and Research, BMBF, grants 03F0462D, 03F0611D, 03F0662D (M. Rhein, R. Steinfeldt, J. Sültenfuß) and grants 03F0462A, 03F0611A, 03F0662A (M. Dengler, T. Fischer). The authors thank captain and crews of the cruises M91, M68/3, P347, and ATA3 for their professional field support. The wind speed data are derived from ftp://ftp.ifremer.fr/ifremer/cersat/products/ gridded/mwf-ascat/data/daily and ftp://ftp.ifremer.fr/ifremer/ cersat/products/gridded/mwf-quikscat/data/daily for the time period of the Peruvian and Mauritanian cruises respectively. The satellite data of primary production can be found at http://www.science.oregonstate.edu/ocean.productivity/index.php. The altimeter products were produced by Ssalto/Duacs and distributed by Aviso with support from CLS-Cnes (http://www.aviso.oceanobs.com/duacs/). The contribution from the group of Arne Körtzinger (GEOMAR), making the nutrient data available, is gratefully acknowledged. We also thank two anonymous reviewers for their valuable comments.

The article processing charges for this open-access publication were covered by the University of Bremen.

Edited by: H. Bange 


\section{References}

Anderson, L. A. A. and Sarmiento, J. L.: Redfield ratios of remineralization determined by nutrient data analysis, Global Biogeochem. Cy., 8, 65-80, 1994.

Behrenfeld, M. J. and Falkowski, P.-G.: Photosynthetic rates derived from satellite-based chlorophyll concentration, Limnol. Oceanogr., 42, 1-20, 1997.

Broecker, W. S., Peng, T. H., and Stuiver, M.: An estimate of the upwelling rate in the Equatorial Atlantic based on the distribution of bomb radiocarbon, J. Geophys. Res., 83, 6179-6186, 1978.

Carr, M.-E. and Kearns, E. J.: Production regimes in four Eastern Boundary Current systems, Deep-Sea Res. Pt. II, 50, 3199-3221, doi:10.1016/j.dsr2.2003.07.015, 2003.

Fennel, W.: Theory of the Benguela Upwelling System, J. Phys. Oceanogr., 29, 128-142, 1999.

Fréon, P., Barrange, M., and Aristegui, J.: Eastern boundary upwelling ecosystems: Integrative and comparative approaches, Prog. Oceanogr., 83, 1-14, 2009.

Gill, A. E.: Atmosphere-Ocean Dynamics, Academic Press, California, 662 pp., 1982.

Gruber, N., Lackhar, Z., Frenzel, H., Marchesiello, P., Münnich, M., McWilliams, J. C., Nagai, T., and Plattner, G.-K.: Eddy-induced reduction of biological production in eastern boundary upwelling systems, Nat. Geosci., 4, 787-792, doi:10.1038/NGEO1273, 2011.

Gouriou, Y. and Reverdin, G.: Isopycnal and diapycnal circulation of the upper equatorial Atlantic Ocean in 1983-1984, J. Geophys. Res., 97, 3543-3572, doi:10.1029/91JC02935, 1992.

Hagen, E.: Northwest African upwelling scenario, Oceanol. Acta, 23, S113-S124, 2001.

Haskell II, W. Z., Kadko, D., Hammond, D. E., Knapp, A. N., Prokopenko, M. G., Berelson, W. M., and Capone, D. G.: Upwelling velocity and eddy diffusivity from ${ }^{7} \mathrm{Be}$ measurements used to compare vertical nutrient flux to export POC flux in the Eastern Tropical South Pacific, Mar. Chem., 168, 140-150, doi:10.1016/j.marchem.2014.10.004, 2015.

Kadko, D. and Johns, W.: Inferring upwelling rates in the equatorial Atlantic using ${ }^{7} \mathrm{Be}$ measurements in the upper ocean, Deep-Sea Res. Pt. I, 58, 647-657, doi:10.1016/j.dsr.2011.03.004, 2011.

Karstensen, J., Stramma, L., and Visbeck, M.: Oxygen minimum zones in the eastern tropical Atlantic and Pacific oceans, Prog. Oceanogr., 77, 331-350, 2008.

Kiefhaber, D., Zappa, C. J., and Jähne, B.: Influence of natural surfactants on short wind waves in the coastal Peruvian waters, Ocean Sci. Discuss., 12, 1291-1325, doi:10.5194/osd-12-12912015, 2015.

Klein, B. and Rhein, M.: Equatorial upwelling rates inferred from helium isotope data: a novel approach, Geophys. Res. Lett., 31, L23308, doi:10.1029/2004GL021262, 2004.

Kock, A., Schafstall, J., Dengler, M., Brandt, P., and Bange, H. W.: Sea-to-air and diapycnal nitrous oxide fluxes in the eastern tropical North Atlantic Ocean, Biogeosciences, 9, 957-964, doi:10.5194/bg-9-957-2012, 2012.

Levitus, S.: Climatological Atlas of the World Ocean, NOAA Professional Paper 13, US Gov. Printing Office, Washington, DC, 117 pp., 1982.

Liss, P. S. and Merlivat, L.: Air-sea gas exchange rates: introduction and synthesis, in: The Role of Air-Sea Exchange in Geochemical
Cycling, edited by: Buat-Ménard, P., D. Reidel, Norwell, Mass, 113-127, 1986.

Lupton, J.: Terrestrial inert gases - isotope tracer studies and clues to primordial components in the mantle, Annu. Rev. Earth Pl. Sc., 11, 371-414, 1983.

Martin, A. P. and Richards, K. J.: Mechanisms for vertical nutrient transport within a North Atlantic mesoscale eddy, Deep-Sea Res. Pt. II, 48, 757-773, 2001.

Mazzini, P. L. F. and Barth, J. A.: A comparison of mechanisms generating vertical transport in the Brazilian coastal upwelling regions, J. Geophys. Res., 118, 5977-5993, doi:10.1002/2013JC008924, 2013.

McClain, C. R.: An Investigation of Ekman Upwelling in the North Atlantic, J. Geophys. Res., 98, 12327-12339, 1993.

McGillicuddy Jr., D. J., Anderson, L. A., Bates, N. R., Bibby, T., Buesseler, K. O., Carlson, C. A., Davis, C. S., Ewart, C., Falkowski, P. G., Goldthwait, S. A., Hansell, D. A., Jenkins, W. J., Johnson, R., Kosnyrev, V. K.,Ledwell, J. R., Li, Q. P., Siegel, D. A., and Steinberg, D. K.: Eddy/wind interactions stimulate extraordinary mid-ocean plankton blooms, Science, 316, 1021-1026, doi:10.1126/science.1136256, 2007.

Minas, H. J., Minas, M., and Packard, T. T.: Productivity in upwelling areas deduced from hydrographic and chemical fields, Limnol. Oceanogr., 31, 1182-1206, 1986.

Nightingale, P. D., Malin, G., Law, C. S., Watson, A. J., Liss, P. S., Liddicoat, M. I., Boutin, J., and Upstill-Goddard, R. C.: In situ evaluation of air-sea gas exchange parameterizations using novel conservative and volatile tracers, Global Biogeochem. Cy., 14, 373-387, 2000.

Oakey, N. S.: Determination of the rate of dissipation of turbulent energy from simultaneous temperature and velocity shear microstructure measurements, J. Phys. Oceanogr., 12, 256-271, 1982.

Osborn, T. R.: Estimates of the local rate of vertical diffusion from dissipation measurements, J. Phys. Oceanogr., 10, 83-89, 1980.

Oschlies, A. and Garçon, V.: Eddy induced enhancement of primary pruduction in a model of the North Atlantic Ocean, Nature, 394, 266-269, 1998.

Prandke, H. and Stips, A.: Test measurements with an operational microstructure-turbulence profiler: Detection limits of diffipation rates, Aquat. Sci., 60, 191-209, 1998.

Quay, P. D., Stuiver, M., and Broecker, W. S.: Upwelling rates for the equatorial Pacific Ocean derived from the bomb ${ }^{14} \mathrm{C}$ distribution, J. Mar. Res., 41, 769-792,1983.

Rhein, M., Dengler, M., Sültenfuß, J., Hummels, R., HüttlKabus, S., and Bourles, B.: Upwelling and associated heat flux in the equatorial Atlantic inferred from helium isotope disequilibrium, J. Geophys. Res., 115, C08021, doi:10.1029/2009JC005772, 2010.

Schafstall, J., Dengler, M., Brandt, P., and Bange, H.: Tidalinduced mixing and diapycnal nutrient fluxes in the Mauritanian upwelling region, J. Geophys. Res., 115, C10014, doi:10.1029/2009JC005940, 2010.

Stramma, L., Bange, H. W., Czeschel, R., Lorenzo, A., and Frank, M.: On the role of mesoscale eddies for the biological productivity and biogeochemistry in the eastern tropical Pacific Ocean off Peru, Biogeosciences, 10, 7293-7306, doi:10.5194/bg-10-72932013, 2013. 
Sültenfuß, J., Rhein, M., and Roether, W.: The Bremen mass spectrometer facility for the measurement of helium isotopes, neon, and tritium in water, Isot. Environ. Health S., 45, 1-13, 2009.

Tanhua, T. and Liu, M.: Upwelling velocity and ventilation in the Mauritanian upwelling system estimated by CFC-12 and $\mathrm{SF}_{6}$ observations, J. Mar. Sys., 151, 57-70, doi:10.1016/j.jmarsys.2015.07.002, 2015.

Tanhua, T., van Heuven, S., Key, R. M., Velo, A., Olsen, A., and Schirnick, C.: Quality control procedures and methods of the CARINA database, Earth Syst. Sci. Data, 2, 35-49, doi:10.5194/essd-2-35-2010, 2010.

Toggweiler, J. R., Dixon, K., and Broecker, W. S.: The Peru upwelling and the ventilation of the South Pacific thermocline, J. Geophys. Res.-Oceans, 96, 20467-20497, 1991.
Tsai, W. T. and Liu, K. K.: An assessment of the effect of sea surface surfactant on global atmosphere-ocean $\mathrm{CO}_{2}$ flux, J. Geophys. Res., 108, 3127, doi:10.1029/2000JC000740, 2003.

Wanninkhof, R., Feely, R. A., Atwood, D. K., Berberian, G., Wilson, D., Murphy, P. P., and Lamb, M. F.: Seasonal and lateral variations in carbon chemistry of surface water in the eastern equatorial Pacific during 1992, Deep-Sea Res. Pt. II, 42, 387409, 1995.

Weingartner, T. J. and Weisberg, R. H.: On the annual cycle of equatorial upwelling in the central Atlantic ocean, J. Phys. Oceanogr., 21, 68-82, 1991.

Yoshida, K.: Coastal upwelling off the California coast, Records Oceanogr. Works Japan, 2, 8-20, 1955. 